\title{
KULTUROWE ARCHIWUM BŁĘKITNEJ HUMANISTYKI 2020
}

2020 rok należał do wody! Niniejsze opracowanie pokazuje kulturowy wzrost zainteresowania wodnymi tematami. Jest ono również zaczynem planowanego cyfrowego archiwum błękitnej humanistyki w regionie Europy Środkowo-Wschodniej. Autorka opracowania skupiła się na polskim kontekście, a kluczem wyboru zaprezentowanych przykładów były realizacje artystyczne (wystawy, spektakle, performance, koncerty), kuratorowane rezydencje, dyskusje i słuchowiska zrealizowane w 2020 roku, dotyczące tematyki wodnej, okołowodnej, a także widocznej potrzeby zmiany naszego stosunku do środowisk wodnych.

\section{STYCZEŃ 2020}

Wystawa BOBSCHE COMBO (Flow \& < dienstag abend>feat. Luxus) w Austriackim Forum Kultury w Warszawie. Odbyła się ona po plenerze na Wiśle w 2019 roku w ramach wodnej rezydencji Flow/Przepływ, w której wzięli udział członkowie grupy Luxus oraz inni badacze, artyści aktywiści z Polski i Austrii. Uczestnicy wodnej rezydencji ,wspólnie eksplorowali dziką naturę rzeki oraz szukali form artystycznego współbycia".

Artystki i artyści: Brishty Alam, Agnieszka Brzeżańska, Ewa Ciepielewska, Vasilis Flouris, Mateusz Grzesiak, Christina Gruber, Bożena Grzyb Jarodzka, Paweł Jarodzki, Linda Lemon, Szymon Lubiński, Albert Mayr, Phelim McConigly, Janusz Perenc, Katrin Plavcak, Alicja Rogalska, Nicole Sabella, Paulina Semkowicz, Sophie Thun, Dorota Walentynowicz, Krzysztof Wałaszek.

Kurator: Stanisław Welbel.

Wydarzeniem w ramach wystawy była rozmowa BOBSCHE COMBO: Naturalna retencja i regulacja rzek $\mathrm{z}$ dr. Przemysławem Nawrockim (WWF Polska), Romanem Głodowskim (Stowarzyszenie „Nasz Bóbr”) i Koalicją Ratujemy Rzeki. Dyskusja była moderowana przez Agnieszkę Brzeżańską oraz Ewę Ciepielewską (18.01.2020). 5.12.2019-24.01.2020

https://austria.org.pl/wydarzenia/bobsche-combo 


\section{LUTY 2020}

Happening protestacyjny Modraszki do boju! Powstrzymajmy dewastację Zakrzówka - zmieńmy projekt! Kolektyw Modraszki powstały z inicjatywy artystki Cecylii Malik w Krakowie ma na celu ochronę terenów zielonych nad zbiornikiem wodnym na Zakrzówku. Sam happening miał przekonać Radnych Krakowa do zmiany projektu „Rewitalizacja Zakrzówka” na taki, który uwzględnia potrzeby wszystkich mieszkańców Krakowa oraz uszanuje tamtejszy ekosystem.

26.02.2020

https://www.facebook.com/events/501145787483815/

\section{MARZEC 2020}

Wystawa Seriously Salt / nowe materializacje w Galerii Entropia we Wrocławiu. Na ekspozycję składały się „mocno posolone” elektroniczne odpady ze skrystalizowaną solą oraz wideo ukazujące morze niestrudzenie bijące falami o nabrzeże.

Artystka: Izabela Chamczyk.

26.03.2020-16.04.2020

https://entropia.art.pl/view_news.php?id=571\&arc=1\&year=2020

\section{KWIECIEŃ, MAJ, CZERWIEC 2020}

Wystawa Wiek pólcienia. Sztuka w czasach planetarnej zmiany w Muzeum Sztuki Nowoczesnej w Warszawie, na którą składały się prace artystyczne z ostatnich pięciu dekad, bazujące na obserwacji i wizualizacji przemian zachodzących na kuli ziemskiej. Była to przestrzeń do dyskusji na temat ,zarządzania nieodwracalnym” oraz nowych form solidarności, empatii i bycia razem w obliczu kryzysu klimatycznego.

Kuratorzy: Jagna Lewandowska, Sebastian Cichocki.

Artystki i artyści: Jonathas de Andrade, Isabelle Andriessen, Rasheed Araeen, Robert Barry, Kasper Bosmans, Boyle Family, Agnieszka Brzeżańska, Dora Budor, Vija Celmins, Center for Land Use Interpretation, Alice Creischer, Czekalska + Golec, Betsy Damon, Tacita Dean, Thierry De Cordier, Agnes Denes, Ines Doujak, Jimmie Durham, Jerzy Fedorowicz, Hamish Fulton, Futurefarmers, Cyprien Gaillard, Simryn Gill, Wanda Gołkowska, Guerrilla Girls, Małgorzata Gurowska, Anna \& Lawrence Halprin, Mitsutoshi Hanaga, Suzanne Husky, Ice Stupa Project, INTERPRT, Anja Kanngieser, Karrabing Film Collective, Beom Kim, Frans Krajcberg, Susanne Kriemann, Stefan Krygier, Katalin Ladik, Nicolás Lamas, John Latham, Richard Long, Antje Majewski, Nicholas Mangan, Krzysztof Maniak, Qavavau Manumie, Robert Morris, Shana Moulton \& Nick Hallett, Teresa Murak, Peter Nadin \& Natsuko Uchino \& Aimée Toledano, Bruce Nauman, Nishiko, Isamu Noguchi, OHO, Dennis Oppenheim, Prabhakar Pachpute \& Rupali Patil, Maria Pinińska-Bereś, Agnieszka 
Polska, Ludmiła Popiel, Joanna Rajkowska, Jerzy Rosołowicz, Oscar Santillán, Gerry Schum, Bonnie Ora Sherk, Anna Siekierska, Rudolf Sikora, Magdalena Starska, Irv Teibel, Akira Tsuboi, Maria Waśko, Ryszard Waśko, Lawrence Weiner, Magdalena Więcek, Andrea Zittel.

\subsubsection{0-13.09.2020}

https://artmuseum.pl/pl/wystawy/wiek-polcienia

Seminaria filozoficzne z cyklu Wiek półcienia w Muzeum Sztuki Nowoczesnej w Warszawie:

Prowadzący: Adrian Krupa, Bernard Wnuk.

Forum Pólcienia (https://artmuseum.pl/pl/wydarzenia/forum-polcienia-seminarium-filozoficzne), 26.04.2020; Czym jest płynny feminizm (https://artmuseum.pl/pl/doc/ audio-czym-jest-plynny-feminizm), 10.05.2020; Jak dostrzec Antropocen? (https:// artmuseum.pl/pl/wydarzenia/jak-dostrzec-antropocen-seminarium-filozoficzne), 24.05.2020.

Wykłady z cyklu Wiek półcienia w Muzeum Sztuki Nowoczesnej w Warszawie: Fonopoetyka srebrnego roweru - dźwięk w twórczości Katalin Ladik, wykład Antoniego Michnika (https://artmuseum.pl/pl/wydarzenia/fonopoetyka-srebrnego-roweru-dzwiek-w-tworczosci-katalin), 15.05.2020; O źródłach refleksji klimatycznej w polskiej sztuce, wykład Magdaleny Worłowskiej (https://artmuseum. $\mathrm{pl} / \mathrm{pl} /$ wydarzenia/o-zrodlach-refleksji-klimatycznej-w-polskiej-sztuce-wyklad), 29.05.2020; Więcej niż przetrwanie. Krytyczne oświecenie i przedstawianie globalnego ocieplenia, wykład Joanny Bednarek (https://artmuseum.pl/pl/wydarzenia/wiecej-niz-przetrwanie-krytyczne-oswiecenie-i-przedstawianie), 19.06.2020.

Wystawa Scenariusze przyszłości w Tytano na Dolnych Młynach w Krakowie. W prezentowanej realizacji wideo o tym samym tytule Scenariusze przyszłości autorzy wizualizują nadchodzące osiemdziesiąt jeden lat na Ziemi. Hipotetyczne scenariusze klimatyczne są ukazane za pomocą czterech ścieżek zdarzeń. Wystawa powstała w ramach Miesiąca fotografii 2020 w Krakowie.

Artyści: Lena Dobrowolska oraz Teo Ormond-Skeaping.

26.06.2020-19.07.2020

https://photomonth.com/pl/portfolio/lena-dobrowolska-i-teo-ormond-skeaping/

Wystawa WetWare: Poliferacja i Przeczucie w Instytucie Cybernetyki Sztuki (ICS) w Galerii Spiż 7 w Gdańsku. Wystawa proponuje namysł nad dziełami sztuki i aktywnościami artystycznymi poprzez pryzmat terminu WETWARE - rozrostu struktur biologicznych. Dzieła sztuki w ich materialnym aspekcie zostały potraktowane jako nośniki informacji programujące i stymulujące przebieg procesów społecznych. Kuratorzy: Marek Rogulski, Dorota Grubba-Thiede (współpraca kuratorska). 
Artystki i artyści: Marcin Bożek, Marta Branicka, Flora Ćwirko + Jan Maurycy Adamski, Jowan Czerkas, Urszula Dulewicz, Dorota Grubba Thiede + Danuta Ćwirko Godycka, Tomasz Kopcewicz, Marta Koniarska, Maria Krupa, Monika Krygier + Stefan Krygier + Włodzimierz Pietrzyk, Przemysław Kryszk, Ryszard Ługowski, Krzysztof Malec, Anna Malinowska, Andrzej Egon Fietke Miastkowski, Piotr Tadeusz Mosur, Mateusz Pęk, Katarzyna Podpora, Marek Rogulski, Magdalena Rosman, Patryk Różycki, Wojtek Sosnowski, Urszula Śliz, Xenia Uranova, Marcelo Zammenhoff, Sofia Żezmer.

Częścią wystawy WETWARE: PROLIFERACJA I PRZECZUCIE byla indywidualna wystawa Marka Rogulskiego: WETWARE. Sala pamięci.

20.06.2020-22.06.2020

https://zbrojowniasztuki.pl/wydarzenia/archiwum/wetware-proliferacja-i-przeczucie, 2824

Pokaz filmowy Kino w Otwartej Stoczni w CSW Wiewiórka w Krakowie zrealizowanych przez krakowskich artystów, gdzie rzeka została ukazana w kontekście społeczno-ekologicznym.

6 Rzek (Cecylia Malik), Wisła na starych zdjęciach (Mateusz Niemiec), Zapiski z Księżyca (Bartolomeo Koczenasz).

19.06.2020

https:/www.facebook.com/events/csw-wiewi\%C3\%B3rka/kino-w-otwartej-stoczni/709029626556822/

Wystawa Nie zatrzymasz rzeki. Wystawa Sióstr Rzek i Braci Potoków w CSW Wiewiórka w Krakowie, prezentująca członkinie i członków kolektywu Sióstr Rzek. Na wystawie znalazły się: dokumentacja fotograficzna protestów, performensów, happeningów i spływu Wisłą, oraz indywidualne prace artystyczne zrealizowane przez Siostry Rzeki.

SIOSTRY RZEKI: Agata Bargiel (WISŁA), Anna Chmiel (GOŁCZANKA), Magda Drągowska, Anna Gotfryd-Kolecka (CZARNA ORAWA), Anna Górka (DUNAJEC), Justyna Górowska (SKAWA), Ania Grajewska (GLINNA), Małgo Grygierczyk (SOŁA), Monika M Jarecka (PAKLICA), Monika Łabędzka (BUDKOWICZANKA), Anuszka Łachowska (MARYCHA), Anna Malik (DUNAJEC), Cecylia Malik (BIAŁKA), Agata Mazur (TANEW), Aga Miłogrodzka (ŁYNA), Kasia Pilitowska (SZTOŁA), Dominika Serzysko (ODRA), Grażyna Smalej (UHERKA), Zosia Szyrajew (BUG). LUBUSKIE SIOSTRY RZEKI: Justyna Budzyn (MYŚLA), Krystyna Dziewiałtowska-Gintowt (KŁODAWKA); SIOSTRY RZEKI MEANDRUJĄCE, WSPIERAJĄCE: Atakamakata, Basia Budniak (NIELBA/WEŁNA), Dobrawa Borkała, Ewa Ciepielewska (WISŁA), Katarzyna Dorota, Małgorzata Gniadek Drozd (PORONIEC), Urszula Dziurdzia, Agnieszka Gołębiowska (WIERNA RZEKA), Gosia Grodzka (OLZA), Aneta Lazurek (DUNAJEC), Paulina Karpowicz (WIEPRZ), Małgorzata Markiewicz (RABA), Martyna Markiewicz, Joanna Monasterska 
(WISŁA), Hania Mac, Bianka Rolando, Małgorzata Rutkowska (PISIA TUCZNA), Jagoda Rybkowska (KAMIENICA), Marta Sala (CHECHŁO), Ewelina Smereczyńska, Sutari (MARYCHA, OŁAWA, SZESZUPA), Ewa Szlachetka-Depak (KAMIENNA), Beata Tarnawa, Elżbieta Tomczyk-Miczka, Małgorzata Tylec (STRADOMKA), Agnieszka Węglarska Grafisk, Marta Majka Wiśniewska, Marysia Wrońska.

Wydarzeniem towarzyszącym wystawie była pieśń plynie jak rzeka - spotkanie z pieśniami tradycyjnymi wykonana przez zespół SWADA, Strojone oraz DOLA Zespół pieśni bez tańca.

\subsubsection{0-14.07.2020}

https://cswwiewiorka.tumblr.com/post/621986340563779585/nie-zatrzymasz-rzeki-wystawa-si\%C3\%B3str-rzek-i-braci

9 Wodna masa krytyczna na Wiśle organizowana przez CSW Wiewiórka w Krakowie. Rokroczny spływ fragmentem Wisły na stworzonych przez uczestników pojazdach wodnych. Wydarzenie ma na celu zwrócenie uwagi mieszkańców na problem dbania o rzeki i często zbyt dużą ingerencję człowieka w ich naturalny bieg.

\subsubsection{0}

https://wodnamasa.tumblr.com/

Rezydencja artystyczna na Wiśle oraz Narwi $\boldsymbol{F L O W}$. Organizowane przez Agnieszkę Brzeżańską i Ewę Ciepielewską plenerowe działania twórcze kontynuowane każdego roku we współpracy z Fundacją Razem Pamoja (od 2016 roku). Planowane działania oraz spontaniczne zdarzenia zwracają uwagę na określoną dynamikę - wielowątkowość i wielogatunkowość otaczającego uczestników ekosystemu, aktywując odmienne formy poruszania się, komunikacji, podziału czasu na okres pracy i rekreacji.

Artystki i artyści: Helenka Siemińska, Ania Brzozowska, Wojtek Józefowicz, Basia Grzebulska, Dobrawa Borkała, Basia Borkała, Mateusz Grzesiak, Krysia Grzesiak, Marta Gonczarko, Marysia Madej, Diana Lelonek, Iza Koczanowska, Piotr Jedynasiak - drugi sternik, pp. Prusinowscy: Kaja, Janusz, córka Hania i dwóch synów, Sophie Thun, Linda Lemon, Janusz (Jajuż), Tomek Wichowski, Igor Kubik, Kuba Falkowski, Alicja Wysocka, Grupa Luxus: Bożenka i Paweł Jarodzcy, Yola Ponton, Marta Jankowska, Joasia Wójtowicz, Magda Lazar, Marta Niedbał, Maja Demska, Basia Jańczak, Ola Liput, Magda Mosiewicz, Tomasz Kosa Kosobudzki, Jarek Lustych, Rafał Chwiszczuk, jego żona Marta i syn Noe, Rafał Żarski, Tomek Pawłowski, Władek Markowski, Magda Kościsz, Dominika Olszowy, Justyna Górowska, Łukasz Roth, Zeynab Gueye, Szymon Zachariasz, Dorota Walentynowicz, Paulina Malczewska, Agnieszka Brzeżańska i Ewa Ciepielewska.

Organizatorzy: Ewa Ciepielewska / Agnieszka Brzeżańska we współpracy z Fundacją Razem Pamoja.

28.06.2020-17.08.2020

https://www.facebook.com/flowprzeplyw/ 


\section{LIPIEC 2020}

Projekt Jaka woda? w Biennale Warszawa. Autorka Małgorzata Owczarska zaprasza do rozmowy nad znaczeniem wody z perspektywy antropologicznej z kobietami: m.in. fizyczką, rolniczką, inżynierką, ratowniczką morską czy starszą z ludu Algonquin. Nagrania były sukcesywnie umieszczane na stronie internetowej Biennale Warszawa.

Autorka: Małgorzata Owczarska.

Humanistyka z fizyczka $w$ wodzie, rozmowa z dr Aleksandrą Kardaś, 10.07.2020

O „Pieśni wody”, rozmowa z Babcią Nancy Andry, 12.07.2020

$O$ wodzie, rolnictwie $i$ dostepie do wody pitnej w Kirgistanie cz. 1, rozmowa z Agnieszką Makowską, 13.07.2020

$O$ wodzie, rolnictwie $i$ dostępie do wody pitnej w Kirgistanie cz. 2, rozmowa z Agnieszką Makowską, 16.07.2020

O wodzie $w$ mieście i btękitno-zielonej infrastrukturze, rozmowa z Iwoną Wagner, 21.07.2020

O morzu i wodzie z ratowniczką morska, rozmowa z Iwoną Kołodziejską, 27.07.2020

$O$ renaturyzacji rzeki $i$ doradztwie środowiskowym, rozmowa z Iloną Biedroń, 14.08.2020

https://biennalewarszawa.pl/jaka-woda/

Podcast Woda jest Toba w ramach Generatora Malta w Poznaniu. W poszczególnych odcinkach podcastu prowadząca z zaproszonymi gośćmi zastanawiała się nad społecznymi kontekstami wody. Z aktywistkami i artystami dyskutowała, jakie więzi i połączenia stwarza - nie tylko na poziomie relacji ludzko-ludzkich i ludzko-zwierzęcych, ale także ekonomicznych i politycznych.

Prowadząca: Ola Juchacz.

10.07.2020, ODCINEK 1: Znikające ekosystemy, rozmówczyni: Adriana Molenda 24.07.2020, ODCINEK 2: Feminizm i nurkowanie, rozmówczynie: Kolektyw Nurkowy Bojka

7.08.2020, ODCINEK 3: Hydrosztuka, rozmówczyni: Ewelina Jarosz

21.08.2020, ODCINEK 4: Matka Polka / Siostra Rzeka, rozmówczyni: Cecylia Malik 4.09.2020, ODCINEK 5: Retencja w mieście, rozmówczyni: Agnieszka Antonowicz https://malta-festival.pl/pl/program/podcast-woda-jest-toba-odcinek-1-znikajace-ekosystemy

Premiera mapy internetowej Jeziora Wielkopolski Darii Mielcarzewicz podczas Generatora Malta w Poznaniu. Internetowa odsłona projektu to chęć podzielenia się jeziornymi historiami, ale również zachęcenia do szukania własnych, przyrodniczych włóczęg.

\subsubsection{0}

https://jeziorawielkopolski.pl/ 
Wydarzenie Requiem dla Warty pod mostem Rocha Poznańskiej Orkiestry Improwizowanej w ramach Generatora Malta w Poznaniu. Poznańska Orkiestra Improwizowana zaprosiła na ostatnie pożegnanie tutejszych rzek. Kilkunastu muzyków przy użyciu m.in. saksofonu, kornetu, klarnetu, bębnów obręczowych, ukulele, kontrabasu, trąbki, modulara, metalowych odpadów i głosu odegrało skomponowane specjalnie na tę okazję żałobno-komediowe requiem dla rzek oraz wykonało wiele wodnych rytuałów w skromnych, toksycznych pozostałościach Warty i Cybiny.

22.07.2020

https://malta-festival.pl/pl/program/requiem-dla-warty-poznanska-orkiestra-improwizowana/pl

Premiera Protest songu - Woda jest Toba, CUKRY (Maria Ornaf i Zuzanna Zachara-Hassairi). Woda jest toba to protest song i krótka opowieść filmowa powstałe z rozważań wokół społecznych kontekstów wody i projektów artystyczno-badawczych, które eksplorują ten temat w ramach Generatora Malta.

26.07.2020

https://malta-festival.pl/pl/program/premiera-protest-songu-woda-jest-toba-cukry-maria-ornaf

Spektakl Turnus mija, a ja niczyja. Operetka sanatoryjna (Teatr im. J. Słowackiego w Krakowie) podczas Generatora Malta w Poznaniu. Spektakl opowiada o grupie biznesmenów, którzy przyjeżdżają do sanatorium, aby zapoznać się z potencjałem uzdrowiska i ewentualnie weń zainwestować (,w 2035 roku woda będzie droższa od ropy”); koniec końców, stają się kuracjuszami.

Reżyser: Cezary Tomaszewski.

9.07.2020

https://teatrwkrakowie.pl/spektakl/turnus-mija-a-ja-niczyja

\section{SIERPIEŃ 2020}

Wystawa Wodowanie w Galerii Sztuki Współczesnej w Opolu. Wystawa była rezultatem projektu artystek zrealizowanego wraz z mieszkańcami Opola nad kąpieliskiem Bolko, podczas którego czytano fragmenty książek, dyskutowano o sztuce w kontekście wody i wspólnie pływano w wyrobisku.

Artystki: Gaja Karolczak \& Natalia Krawczyk.

11.08.2020-13.09.2020

https://galeriaopole.pl/wustawa-wodowanie-/

Wystawa Woda jest Toba w Pływalni Olimpia w ramach Generatora Malta w Poznaniu. Była to finałowa wystawa Generatora Malta, która podsumowała kilkumiesięczne 
działania artystek i aktywistów krytycznie przyglądających się relacji człowieka i wody z perspektywy lokalnej i globalnej.

Kuratorka: Joanna Pańczak.

Koordynacja: Sonia Borkowicz, Patryk Moszka, Mateusz Nowacki, Joanna Spychała.

Produkcja: Bartosz Górski, Anna Zalejska.

Artystki i artyści: Kolektyw Nurkowy Bojka, Pamela Bożek, CUKRY (Maria Ornaf i Zuzanna Zachara-Hassairi), Ola Juchacz, Mateusz Kowalczyk, Daria Mielcarzewicz, Małgorzata Myślińska, Kolektyw Przepływ.

Wykład dr Marty Kubackiej Antropopresja lokalnych zbiorników wodnych.

\subsubsection{0-30.08.2020}

https://malta-festival.pl/pl/festival/news/woda-jest-przywilejem-prawem-ryzykiem-przyjemnoscia-zyciem

Premiera Studnia/Gtosowanie Pameli Bożek w ramach Generatora Malta w Poznaniu. Na potrzeby projektu Pamela Bożek stworzyła raport artystyczny poświęcony zbiórkom publicznym na budowy studni w krajach Afryki.

\subsubsection{0-6.09.2020}

https://malta-festival.pl/pl/program/studnia--glosowanie-pamela-bozek-2

Debaty Woda - Kryzys - Migracje (Poznańska Garażówka) w ramach Generatora Malta w Poznaniu. Cykl trzech dyskusji poświęconych relacji między tym, co związane z wodą a zjawiskiem migracji. Odpowiada na pytania, jak możemy opisać, powiązać i analizować zależności dotyczące eksploatacji zasobów wodnych ze zmianami klimatu, sytuacją polityczną, niezadowoleniem społecznym i tzw. kryzysem uchodźczym.

Prowadzenie: Katarzyna Czarnota.

29.07.2020, goście: Anna Skowera, Przemysław Wielgosz, Filip Wesołowski

12.08.2020, goście: Gustavo Carvalho, prof. dr hab. Jacek Piskozub, Łukasz Łyskawka, Katarzyna Słubik

26.08.2020, goście: organizacja Sea Watch, Pamela Bożek

https://malta-festival.pl/pl/program/debata-woda-kryzysy-migracje-poznanska-garazowka

Performans Krystyny Larna Szydłowskiej Potrzebuję Cię jak wody w ramach Generatora Malta w Poznaniu. Lokalny projekt choreograficzno-muzyczny, w którym poprzez gest, ruch i dźwięk podjęto próbę uchwycenia globalnej relacji między wodą a człowiekiem oraz zagłębiono się w naturę tego żywiołu.

\subsubsection{0}

https://malta-festival.pl/pl/program/potrzebuje-cie-jak-wody-krystyna-lama-szydlowska 
Finał projektu H2O The future will involve us w ramach Generatora Malta w Poznaniu. Młodzi twórcy, muzycy, aktywistki i filmowcy spotykają się w kilkudziesięcioosobowej grupie, by wspólnie opracować plan operacyjny o utopijnej nazwie: p r z y s z ło ść.

Kuratorka: Agnieszka Róż.

26.08.2020, Zielona Trawka Pictures / Kino Muza

27.08.2020, Młoda woda, Młoda Kultura / fontanna na placu Wolności

27.08.2020, Wet fingers, Ludzie DoWody / start: Warta

28.08.2020, Wet fingers, Ludzie DoWody / basen Olimpia

29.08.2020, Mitologia klimatyczna, Aqurat / Jezioro Rusałka

https://malta-festival.pl/pl/program/the-future-will-involve-us-h2o

\section{WRZESIEŃ 2020}

Instalacja i performans Siostry Ohydki i Brudna Rzeka w Pawilon Otwarty 2.0. w Poznaniu. Działanie solidaryzujące z zanieczyszczonymi rzekami, które poddawane są dziś brutalnym regulacjom i nadużyciom dla zysku, mające na celu wypracowanie nowej sensorycznej wrażliwości.

Artystki: Wiktoria Bukowy, Julka Walkowiak, Daniel_a Weiss.

Wsparcie merytoryczne: Karolina Kubik, Ewelina Jarosz.

4.09.2020

http://pawilon.org/wydarzenie/siostry-ohydki-i-brudna-rzeka/

Wystawa Wiatrem po wodzie splynęło w Fundacji Salony w Zielonej Górze. Do konstrukcji prezentowanej na wystawie instalacji wykorzystano odpady znalezione na linii rzeki Złota Łączka oraz przedmioty zebrane od mieszkańców Zielonej Góry. Eksplorując jej łączący potencjał, autorzy spróbowali odtworzyć dawną funkcję, kiedyś źródła wody pitnej, dziś - materiału do stworzenia instalacji.

Autorki i autorzy: Blok Klimatyczny KN Tęcza - oddział koła naukowego Tęcza przy Warszawskiej ASP.

\subsubsection{0}

http://fundacjasalony.pl/pl/pozostale/wiatrem-po-wodzie-splynelo

Wystawa online Bialy szum w Bałtyckiej Galerii Sztuki Współczesnej. Wystawa porusza problem kryzysu klimatycznego, tworząc kameralną opowieść o wodzie i prawdopodobieństwie stopniowego zanikania dostępu do niej.

Artystka: Pamela Leończyk.

16.09.2020

https://bgsw.pl/portfolio/pamela-leonczyk-bialy-szum-w-ramach-rezydencji-artystycznej/ 
Wystawa Noise Aquarium w CSW Łaźnia w Gdańsku. Projekt Noise Aquarium Victorii Vesny dotyczy problemu zanieczyszczenia oceanów falami dźwiękowymi generowanymi przez człowieka. Do stworzenia pracy artystka wykorzystała skany 3D mikroorganizmów tworzących plankton oraz unikatowe techniki naukowego obrazowania. Wszystko po to, by móc zanurzyć odbiorców w „akwarium”, w którym otaczające ich morskie mikro-stworzenia osiągają wielkość wielorybów.

Artystka: Victoria Vesna.

Wizualizacja naukowa: dr Alfred Vendl.

Animacja komputerowa: Martina Fröschl.

Programowanie: Glenn Bristol.

Dźwięk: Paul Peluso.

Naukowe obrazowanie: dr Stephan Handschuch, dr Thomas Schwaha.

18.09.2020-14.10.2020

https:/www.laznia.pl/wystawy/victoria-vesna-noise-aquarium-349/

Wystawa Magiczne zaangażowanie w Galerii Miejskiej Arsenał w Poznaniu. Wystawa była miejscem, w którym spotykały się wątki aktywistyczne, artystyczne, antyfaszystowskie, animistyczne, animalistyczne, antyrywalizacyjne, równościowe, magiczne i queer-feministyczne. Odbywające się w jej ramach wydarzenia miały na celu zdejmowanie ,zaklęć kapitalizmu codziennego”, ukazanie zerwanych więzi pomiędzy światem społecznym a tym, co uznawane potocznie za „,naturalne”.

Kuratorki i kuratorzy: Paweł Błęcki, Kinga Mistrzak, Zofia Nierodzińska, Anna Siekiera.

Artystki i artyści: Jadwiga Anioła, Natala Biało, Anna Błachno, Joanna Borof, Damien Brailly, Michał Chomiuk, Ewa Ciepielewska, Adelina Cimochowicz, Małgorzata Gurowska, Yoanna Gwarek, Hanna Husberg, Cecylia Malik, Olga Anna Markowska, Odłam Źdźbło, Klaudia Paliwoda, Daniel Rycharski, Ola Winnicka / SIORY, Wspólnota międzygatunkowa + .

Premiera filmu dokumentalnego w ramach wystawy Łąki Miejskie, 21.07.2020.

Premiera filmu dokumentalnego w ramach wystawy Ziołem w suszę. Etnogeograficzny dryf meteorologiczny, Sara Grolewska, Anka Gruszka (Dziewczyny w Naturze), 2.09.2020.

\subsubsection{0-15.11.2020}

http://arsenal.art.pl/exhibition/magiczne-zaangazowanie/

Wystawa Co nas przetrwa w Centrum Sztuki Współczesnej Zamek Ujazdowski w Warszawie. Ekspozycja była żyjącym organizmem, świątynią i planem filmowym. Instalacja pompująca wodę, która przypominała krwiobieg, łączyła pomieszczenia podzielone według pięciu żywiołów. Sensualna przestrzeń angażowała wszystkie zmysły, była wypełniona dźwiękami i zapachami ziemi, a ściany pomalowano gliną i popiołem.

Artystka: Ursula Mayer. 
Kuratorka: Anna Czaban.

\subsubsection{0-21.02.2021}

https://u-jazdowski.pl/program/wystawy/ursula-mayer

Ciala $\boldsymbol{z}$ wody w Departamencie Obecności przy Muzeum Sztuki Nowoczesnej w Warszawie. Cykl działań przygotowanych dla działającego przy Muzeum Sztuki Nowoczesnej w Warszawie Departamentu Obecności przez kolektywy Centrum w Ruchu, Grupę Ruchoma i Wspólnotę międzygatunkową/Mszak oraz członkinie i członków ruchu Extinction Rebellion, którzy za pomocą performance'u opowiadali o relacji pomiędzy gatunkiem homo sapiens a wodą.

Elia, Grupa Ruchoma

Tęcza, Anna Siekierska w imieniu Wspólnota międzygatunkowa/Mszak

Ciata $z$ wody, Centrum w Ruchu

26.09.2020

https://www.facebook.com/MuzeumSztukiNowoczesnej/posts/101580451815 $54130 /$

Happening protestacyjny Nie dla Zbiornika Kąty - Myscowa, Chcemy Mostu nie Zapory! w Myscowej. W artystycznym proteście przeciw budowie 43-metrowej zapory i zbiornika Kąty-Myscowa w Beskidzie Niskim wzięli udział mieszkańcy, kobiecy kolektyw Siostry Rzeki, Fundacja Greenmind, Koalicja Ratujmy Rzeki i miłośnicy Beskidu Niskiego.

Organizacja: Siostry Rzeki, Fundacja Greenmind, Koalicja Ratujmy Rzeki. 26.09.2020

https://www.youtube.com/watch?v=BhsClFDWOew

\section{PAŹDZIERNIK 2020}

Spektakl Monstera w Teatr Studio w Warszawie. Monstera wypłynęła z oddechowych i cielesno-emocjonalnych doznań dziewięciu artystek, które na czas pracy nad spektaklem stworzyły krąg wymiany doświadczeń i języków artystycznych. Zanurzona w kobiecych narracjach, polityce oddychania i somatyce Monstera podejmuje wątki relacyjnej natury ciała, jego zmysłowych wycieków oraz niestabilnych granic. Koncepcja, choreografia, reżyseria: Marta Ziółek.

Performerki: Ramona Nagabczyńska, Katarzyna Sikora, Monika Świtaj, Zuza Wrońska, Marta Ziółek.

Tekst: Anka Herbut.

Kostiumy: Pat Guzik.

9.10.2020

https://www.teatrstudio.pl/pl/spektakl/monstera 
Wystawa Brzeginki w Galerii Miejskiej Arsenał w Poznaniu. Bohaterami wystawy były tytułowe słowiańskie boginie, a wystawa - rekonstrukcją ich „naturalnego środowiska", będącą swobodną reinterpretacją mitu o nimfach wodnych. Bezpośrednią inspiracją do stworzenia projektu była kamienna posadzka w przestrzeni galerii, skrywająca skamieniałości korala, amonitów i muszli.

Kuratorka: Ania Batko.

Artystka: Justyna Górowska.

9.10.2020-10.01.2021

http://arsenal.art.pl/exhibition/brzeginki/

\section{LISTOPAD 2020}

Spektakl Ćwiczenia meteorologiczne w Komuna Warszawa w Warszawie. Ćwiczenia meteorologiczne mówią o tym, jak pogoda wpływa na nas i na nasze relacje z innymi, warunkując jednocześnie naszą możliwość przetrwania. Podczas spektaklu polityczność dotycząca kryzysu klimatycznego została przeniesiona na wytwarzane na scenie obiekty/zjawiska atmosferyczne.

Artysta: Piotr Urbaniec.

Dramaturgia: Agata Sieniarska.

7.11.2020

https://komuna.warszawa.pl/cwiczenia-meteorologiczne-rez-piotr-urbaniec/

\section{GRUDZIEŃ 2020}

Słuchowisko Jeszcze jeden wschód stońca w Muzeum Emigracji w Gdyni. Opowieść buduje wizję przyszłości, w której postępujące coraz gwałtowniej zmiany klimatyczne sprawiają, że Trójmiasto i Pomorze stają się wymarzonym miejscem do życia dla Europejczyków. Główne bohaterki słuchowiska Matka i nastoletnia Córka porzucają swój domy w zatopionej Wenecji, aby znaleźć schronienie w Gdyni.

Tekst: Anna Wakulik.

Reżyseria: Krzysztof Czeczot.

W rolach głównych: Agnieszka Grochowska, Leszek Lichota, Łukasz Simlat, Agata Turkot $\mathrm{i}$ inni.

\subsubsection{0}

https://www.gdynia.pl/kalendarz/dostepne-online,8408/jeszcze-jeden-wschod-slonca-sluchowisko,553330

Wszystkie strony internetowe były dostępne w czasie przygotowania opracowania.

Opracowała: dr Justyna Górowska 